\title{
Teaching of Problem Solving in School Mathematics Classrooms
}

\author{
Yew Hoong Leong and Rungfa Janjaruporn
}

\section{Aim and Rationale}

The 1980s saw a world-wide push for problem solving to be the central focus of the school mathematics curriculum since the publication of Polya's book about solving mathematics problems in 1954. However, attempts to teach problem solving typically emphasised the learning of heuristics and not the kind of mathematical thinking used by mathematicians. There appears to be a lack of success of any attempt to teach problem solving within school curriculum. Problem solving strategies learned at lower levels tended to be ignored instead of being applied in their mathematical engagements at the higher levels, possibly because of the routine nature of the high-stake national examinations. The era of mathematical problem solving, its research and teaching and learning in schools ended, ambivalent on research findings and imprecise on recommendations for its teaching in schools. Based on the teaching and research experience of the organising team, we think that problem solving should still be the direction for teaching mathematics in schools. As such, this discussion group is proposed to identify the practices in teaching problem solving in school mathematics classrooms across different parts of the world, and how these practices are linked to the success.

Organizers Co-chairs: Yew Hoong (Singapore), Rungfa Janjaruporn (Thailand); Team Members: Tomas Zdrahal (Czech Republic), Khiok Seng Quek (Singapore), Foo Him Ho (Singapore); Liaison IPC Member: Masataka Koyama (Japan).

\footnotetext{
Y.H. Leong $(\square)$

National Institute of Education, Singapore, Singapore

e-mail: yewhoong.leong@nie.edu.sg

R. Janjaruporn

Srinakharinwirot University, Bangkok, Thailand

e-mail: rungfajan@yahoo.com

(C) The Author(s) 2015 


\section{What Is the Place of Problem Solving in the School Mathematics Curriculum?}

As a result of the publication of Polya's book about solving mathematics problems in 1954, National Council of Teachers of Mathematics and the worldwide educational reforms in school mathematics have recommended the study of problem solving at all levels of the mathematics curriculum. The reform documents indicate that problem solving should be the central focus of these mathematics curricula. It should not be an isolated part of mathematics instruction, it should be an integrated part of mathematics learning. Moreover, there is an expectation in these reform documents that even young students will improve their mathematical knowledge and procedures with understanding of problem solving. As a result of these reforms, problem solving has occupied a major focus in worldwide school mathematics curricula. Problem solving had been identified as both a major goal of instruction and a principal activity in mathematics teaching and learning.

\section{How Much Curriculum Time Is Spent in Problem Solving in Comparison to the Other Components of Mathematics Curriculum?}

By learning problem solving in mathematics, students acquire ways of thinking, habits of persistence and curiosity, and confidence in unfamiliar situations that will serve them well outside the mathematics classroom. In addition, problem solving is one of the basic skills that students must take along with them throughout their lives and use long after they have left school. To improve young student's mathematical knowledge and procedures, it is essential that the teacher should know how to teach problem solving and how to approach problem-solving instruction. They should also identify problem solving as a major goal of instruction and a principal activity in mathematics teaching and learning.

\section{What Is the General Perception on the Importance of Mathematical Problem Solving Among the School Teachers?}

Although worldwide educational reforms in school mathematics have recommended the study of problem solving at all levels of the mathematics curriculum, problem solving remains an unfamiliar idea for most school mathematics teachers. Many teachers lack the knowledge and confidence to teach mathematical problem solving. They also do not recognize the importance of mathematical problem solving in their 
classrooms. As such, the question, "How should we go about helping teachers increase their knowledge and confidence to teach problem solving?" has often been asked, and it is timely to ask whether examine teacher professional development programs that are targeted in this area. Apart from workshops on problem solving for teacher-which is the traditional mode of teacher development - there has been a shift towards models that develop teachers as owners and collaborators of innovations in the teaching of problem solving. One example of the latter is the mathematics problem solving for everyone (MProSE) project based in Singapore. Since three members of the organizing committee are investigators of this project, there was substantial capacity to present the details of MProSE in the DG meetings during the conference, which attracted much interest and lively discussion.

\section{How Is Mathematical Problem Solving Assessed?}

In order to have experience on problem solving, students should be expected to solve various types of problems in their own way on a regular basis and over a prolonged period of time. Non-routine problems and open-ended problems that provide students with a wide range of possibilities for choosing and making decisions should be used. Students should be asked to show their solutions in writing. A student's written work on a problem can be used to help evaluate progress in problem solving. A rubric scoring scale, both holistic scoring and analytic scoring, are methods for evaluating a student's written work on a problem.

In MProSE, the team introduced the "mathematics practical" into problem solving lessons using a "Practical" Worksheet. The students were encouraged to treat the problem-solving class as a mathematics "practical" lesson. The worksheet contains sections explicitly guiding the students to use Pólya's stages and problem solving heuristics to solve a mathematics problem. The scoring rubric focuses on the problem solving processes highlighted in the Practical Worksheet. The rubric allows the students to score as high as $70 \%$ of the total 20 marks for a correct solution. However, this falls short of obtaining a distinction $(75 \%)$ for the problem. The rest would come from the marks in Checking and Extending. The intention is to push students to check and extend the problem (Stage 4 of Pólya's stages), an area of instruction in problem solving that has not been largely successful so far.

\section{Summary}

While the participants of the DG are from a wide range of jurisdictions - and hence different social-educational contexts, there is general agreement that mathematics problems solving of the type advocated originally by Polya and subsequently developed by other researchers remain important but elusive. There are many 
challenges, not least of which is teacher development. It is heartening to notefrom the sharing of participants - that innovative projects were conducted, such as MProSE, to address this challenge.

Open Access This chapter is distributed under the terms of the Creative Commons Attribution Noncommercial License, which permits any noncommercial use, distribution, and reproduction in any medium, provided the original author(s) and source are credited. 